\title{
A COMPARATIVE ANALYSIS OF IDEOLOGICAL CONSTRUCTIONS EMBEDDED IN ENGLISH TEXTBOOKS: A CRITICAL DISCOURSE PERSPECTIVE
}

Tahir Afzal ${ }^{1^{*}}$, Muhammad Ilyas Chishti ${ }^{2}$, Atta Ur Rehman Jadoon ${ }^{3}$, Hammad Mushtaq ${ }^{4}$

${ }^{1 *}$ Research Scholar, Department of English, Foundation University Islamabad, Pakistan; ${ }^{2}$ Assistant Professor, School of Natural Sciences, National University of Sciences and Technology, Islamabad, Pakistan; ${ }^{3}$ Research Scholar, Department of English, Foundation University Islamabad, Pakistan; ${ }^{4}$ Assistant Professor, School of Social Sciences and Humanities, National University of Sciences and Technology, Islamabad, Pakistan.

Email: ${ }^{1 *}$ tahirafzal95@yahoo.com, ${ }^{2}$ ilyas_chishti2007@yahoo.com, ${ }^{3}$ mohammadian.jadoon@ @mail.com,

${ }^{4}$ hammad.mushtaq@s3h.nust.edu.pk

Article History: Received on $24^{\text {th }}$ March 2021, Revised on $25^{\text {th }}$ April 2021, Published on $29^{\text {th }}$ April 2021

\section{Abstract}

Purpose of the study: The subject study aims at investigating the construction of diverse ideologies embedded within English textbooks used in Pakistani settings at the elementary level. The entire study is based on a comparative analysis of English textbooks of Punjab Textbook Board (PTB) and Oxford University Press (OUP) and employs a critical discourse lens for a comprehensive analysis.

Methodology: Based on purposeful sampling, the study hinges on insights of Critical Discourse Studies. Out of various models available in CDA, the study employs Fairclough's Three-Dimensional Model for an extensive qualitative analysis of the selected texts as it is more suited to the dynamics of the subject study. Both micro and macro dimensions of the model were employed for an enriched analysis.

Main Findings: Both textbooks aimed at infusing different cultural and ideological constructions within students. Exercise of power supplemented by a specific religious perspective was also witnessed in constructions of diverse ideologies. The current study hinted at a deliberate effort on the part of the government to preserve religious, national, political, and societal ideologies through PTB English textbooks. On the other hand, OUP English textbooks created consent among the students to accept a specific culture and its embedded ideologies.

Applications of this study: The study can be a useful resource for researchers investigating multiple ideologies in textbooks. Critical discourse examination of both textbooks entails ample advice for textbook developers, authors, and syllabus designers to consider the ideological impacts of the textbooks while devising an all-encompassing and comprehensive curriculum to avoid any conflict at later stages.

Novelty/Originality of this study: Diverse dimensions of textbook analysis have already been conducted, but examination of textbooks through a critical discourse lens is indeed a novel dimension that will not only facilitate the reader but also open up new avenues of research for textbook developers and curriculum designers. Examination of diverse ideological construction is indeed an interesting inquiry.

Keywords: Ideological Constructions, Embedded Ideologies, ESL Textbooks, Identity, Critical Discourse Analysis.

\section{INTRODUCTION}

In Pakistan, linguistics has emerged as a distinct area of educational investigation. Being an emerging field of investigation, a positive paradigm was used by early linguists to explore the linguistic features of the language, which are phonology, grammar, and syntax. Saussure (1960) noted that the tradition of linguistic features of language shifted in the last few decades, and now language came to be regarded as a social fact. Now language is being studied with an interdisciplinary approach that relates it to other branches of knowledge like psychology, sociology, philosophy, politics, gender studies, cultural theory, and others. This approach of linguistic inquiry has widened the scope of language and many other issues related to it. The current study is also an outcome of an interdisciplinary approach.

The Islamic Republic of Pakistan was founded on the basis of Islamic ideology. Hence, Pakistan is our national, religious, and cultural identity. The educational system is the main source for building aforesaid identities, and textbooks play a key role in the construction of our national, religious, and cultural identities. Textbooks of different subjects like Social Studies, Pakistan Studies, Islamic Studies, Urdu, and English taught at different levels play their part in the construction of ideologies. Apart from other subjects, the English language is a part of our curriculum as a compulsory subject that plays a pivotal role in the construction of ideologies (Rahman, 2002).

The government and private sectors are playing their roles in imparting education in the country. The majority of the private sector schools follow the curriculum provided by Oxford University Press in the form of English textbooks. These textbooks are desired to enhance the English language competence of the students. However, there are certain ideologies embedded in these textbooks. English textbooks taught in government schools are desired to represent Pakistan's sociolinguistic background and construct religious, political, societal, cultural, and national identities. (Government of Pakistan, 2006). Lesson plans and textbooks are the main tools used for the implementation of the 
official curriculum of the English language. Westbury (1990) considers that the English language curriculum primarily focuses on the formulation of the fundamentals of traditional knowledge and cultural legacy for pedagogical practice at schools. Textbooks encompass official knowledge and worldviews and stress on certain values that the government desires to impart to the students.

Coursebooks are the guiding forces in the schools that manipulate the minds of the students. Among certain factors influencing students in their routine life, textbook contributes a great deal especially in the countries like Pakistan where students greatly rely on textbooks and consider them a source of authentic knowledge. Students consider that these textbooks provide them accurate information that cannot be challenged at any cost.

At their elementary level, students consider the information provided in the textbooks as accurate and are not capable enough to challenge the legitimacy of the knowledge provided in the textbook. Generally, textbooks are treated as one of the teaching resources in Pakistani schools. These textbooks are supposed to be a source of providing wisdom to the students and positively affect their process of mental and spiritual growth. Students have to expand a great deal of time on these textbooks in attempting different exercises and a variety of activities. At the end of the academic session, students are evaluated from these textbooks (Shah \& Pathan, 2016). Thus, there is a great relationship between students and textbooks. Textbooks construct learners' ideologies, worldviews, and perceptions of the world (Rahman, 2002). Textbooks are capable of constructing and transform society (Mohammed, 2015). Despite being from diverse cultural backgrounds, learners are bound to be influenced by the textbooks to a greater degree. Mohammed (2015) argues that the EFL textbooks designers concentrate on certain ideological views and cultural plans while writing books.

Textbooks are quite similar to the earlier version due to the presentation of similar ideological messages in the stuff produced (SDPI: 2002-03) and the PTB (Punjab Textbook Board) English textbooks still contained religious and nationalist lessons. However, these textbooks were different from the previous ones on account of secular ideologies insisting on observing human rights, promoting friendship with non-Muslims, and showing sympathy and fondness to the citizens having other religious identities. Thus, the inclusion of ideological stuff in the textbooks to propagate the desired ideological messages is an old phenomenon still in practice.

Language plays a significant role in cultural and societal developments attracting researchers to investigate it from different perspectives. Critical Discourse Analysis (CDA), one of the significant areas of linguistic inquiry, provides theoretical and philosophical foundations of Fairclough (1992), van Dijk (1993), and Wodak \& Reisigl (2001). CDA is regarded as an appropriate method to investigate discourse and its impact on the development of certain social and cultural practices in various societal domains (Jorgensen \& Phillips, 2002).

Fairclough (1992) propounds that Critical Discourse Analysis investigates discourse to highlight the construction of the dominant and unequal relations in the text. The establishment of a socio-cognitive framework by van Dijk (1993, 2001) gives another dimension to CDA by theorizing those social systems have an association with social cognition. Wodak and Reisigl's (2001) discursive-historical approach produced another viewpoint based on tracing the issues of political nature, e.g., racial conflict. He further proposes that every chunk of obtainable background information on the particular issue is incorporated to explore and decipher certain dimensions of the given text.

In Fairclough's (1992) opinion, CDA implies that discourse is based on the production of language through speaking and writing, and thus understanding discourse is taken as a social practice. To elaborate his point of view, he proposes that every instance of language use (discourse) is based on the production of language in spoken or written form and that discourse establishes the contact between people involved in the text production and interpretation. Therefore, it is an instance of social practice. Based on this perspective, Fairclough (1992) furnished three dimensions of the discourse.

The current study investigates the content of English language textbooks taught as a compulsory subject at the elementary level in Punjab's government and private sector schools. Thus Critical Discourse Analysis is proposed to be the key method for the qualitative inquiry in the present study. According to Fairclough (2001), although texts and interactions are explored in CDA, they are not investigated straightaway. Instead, the investigation starts with the exploration of social problems and issues. Fairclough (2001) further elaborates on the social problems as the problems encountered by people in their social lives and issues that are dealt with in the domains of sociology, political science, and cultural studies. The textbooks mentioned above are expected to be embedded with such concealed issues and thus paved the way for the researcher to consider CDA as an approach suitable for the discovery of these issues through a three-dimensional model proposed by Fairclough (2003).

\section{Ideology: Main concern of CDA}

Ideology is a term frequently used in a wide range of academic disciplines, from linguistics to social theory, and it is diversely used in these disciplines. In linguistics, ideology is the main concern of Critical Discourse Analysis. Oxford English Dictionary defines ideology as a system of ideas and ideals, and the roots of economic or political theory and policy are constructed by this system (Simpson, 2009).

Ideologies, in general, are connected with social groups, classes, castes, or communities like societal, religious, national, and political, and these ideologies represent their basic interests (Fairclough, 1989). In the context of the present study, the discourse of English language textbooks is charged with ideological messages reflecting a particular kind of 
worldview of a nation. The issues of ideologies (political, national, societal, and national) are significantly elaborated through textbook discourse. Therefore, the intention of the present study is based on the investigation of ideological information implanted in the textbooks propagating students in the desired directions and shaping their mindsets.

In the context of the current research, it is significant to mention that textbooks contain a variety of texts for the researchers to investigate the embedded ideologies. The text of the textbooks serves as a major tool to manipulate the opinion of the public and influence the world view of a nation. The discourse of the textbooks effectively covers the matters related to language, power, and ideology. According to Sajid (2015), the textbooks taught in schools at different levels serve dual functions. On the one hand, the prevailing cultural, economic, and social power is sustained through textbooks.

On the other hand, they serve as a weapon to impose ideological values and disseminate the knowledge desired by the people in power. (Sajid, 2015). Moreover, ideology and national identity is embedded in the textbooks to develop the cultural understanding of the learners (Wang, 2016). However, ideologies presented in the textbooks have compatibility issues for the learners (Alimorad, 2016). Furthermore, textbook designers are well aware of the enforcement of desired ideologies through text (Hamidah, 2017).

\section{Ideologies in textbooks}

According to McGrath (2002), textbooks are the practical implementation of the curriculum representing (implicitly or explicitly) certain specific purposes of education. Textbooks of English, Urdu, Islamic studies, and social studies taught at different levels in Pakistan play their part in constructing different ideologies. As a primary source, textbooks are transmitters of ideologies, including gender, beliefs, and race.

Textbooks, used for teaching a foreign language, deliver certain texts and multimodal resources as examples of the language and culture that is being concentrated, furnishing perceptions of the ideologies, values, and beliefs. Yuen (2011) notes that due to a lack of experience of the target language culture, the users of the textbooks can assume that the entire culture of the target language is presented through the information provided by the language content. Although the learners can have alternate access to understand China apart from the classroom, but the stuff provided in the textbooks remains altogether an official source of knowledge. Most notably, reading and learning from textbooks over time affect the construction of their target language skills as well as contribute significantly in implementing dominant ideologies through textbooks (Liu, 2020), and English language education covers the issues of ideology worldwide (Mirhosseini, 2018).

\section{Ideologies in textbooks taught in Pakistan}

Textbooks produced in-country or out of the country for English language teaching are supposed to propagate a set of particular ideological values. While dealing with the question of ideology, Taki (2008) investigated international and indigenous textbooks used to teach the English language in Iran. Within the Critical Discourse Analysis (CDA) perspective, the researcher applied Fairclough's (1989) model to investigate the selected textbooks within three dimensions of meaning (1) the social relations of the characters produced in the textbook (2) their subject positions, and (3) the content of the produced texts. The study highlighted that a particular discourse very much in line with Western economy and consumerism was presented by the textbooks globally produced to teach English as a foreign language while the culture of indigenous people was represented by EFL textbooks produced locally. Textbooks as a source of representation of a certain way of looking at the world have been authenticated by the scholars worldwide who have questioned the textbooks as disseminating the information legitimized with a particular political agenda both in the indigenous and international context (Apple, 2001; Rahman, 2002). The study guided the researcher to review similar studies done in his context.

In Pakistan, internationally produced textbooks of OUP (Oxford University Press) and locally produced textbooks of PTB are taught at the private and government sector schools. The researcher reviewed similar studies (Taki, 2008) conducted in Pakistan and noted that there had been no published work dealing with comparative analysis of the English language textbooks of OUP (international) and PTB (local) taught at the elementary level. Therefore, to encode the ideological messages hidden in the textbooks used for teaching English at the elementary level in government and private sector schools in Punjab, the researcher applied a critical discourse analysis method. As highlighted earlier, the teaching of language and publication of the textbooks are believed to be ideologically weighed down and power-driven. Consequently, the current study deals with the analysis of ideological constructs implanted in English language textbooks taught at the elementary level in Punjab.

According to Rahman (2002), language, power, and ideology are interconnected to each other, and language plays a vital part in disseminating various ideologies; political, religious, etc. While investigating the English language textbooks taught at different schools in Pakistan, Afzaal (2020) explored the ideological stuff related to religion, nationalism, culture, and racism available in the textbooks used for the teaching of the English language. The study had a thin data of 300-350 questionnaires for a population of one hundred and forty million. The researcher noted the presence of diverse themes on the ideologies mentioned above in English language textbooks of government, non-elite, and elite schools having an impact on the attitude of the students learning the English language through these textbooks. The response of 
the research participant to the questionnaire highlighted that the students from elite schools were less religious and nationalistic compared to the students from government and non-elite schools who were observed as more racist and closer to indigenous languages, values, and norms. The study's most significant finding is that the power lies in the English language and the culture nearer to it or its culture. Those retaining it can easily enter the spheres of power compared to those (the lower and middle classes) who do not retain it. On the other hand, Ali et al. (2019) investigated the propagation of ideologies through textbooks and noted the depiction of national and religious ideology in the textbooks.

Textbooks used for the teaching of the English language in Pakistan are embedded with cultural ideologies. While investigating the impact of implicit and explicit ideological messages related to culture, Yaqoob (2011) explored the textbooks used for the teaching of the English language at the secondary level. The study analyzed two different sets of textbooks, i.e., Punjab Textbook Board (PTB) published textbooks used in government and non-elite schools and Oxford University Press (OUP) textbooks used in elite schools. In order to expose the cultural themes presented in these textbooks, the researcher explored the textbooks within the Critical Discourse Analysis (CDA) perspective and employed Fairclough's (2003) model. The analysis indicated that the cultural ideologies were embedded in the textbooks published by the Punjab Textbook Board (PTB) and Oxford University Press (OUP) for the teaching of English at the secondary level.

Moreover, these textbooks presented different cultural ideologies influencing their readers with diverse perspectives. The study highlighted that almost identical perspectives were held by the students studying in government and non-elite schools. Whereas students from elite schools are studying OUP books were having different perspectives on most of the themes mentioned above. In contrast to OUP textbooks, the researcher noted that PTB textbooks were more religious and nationalistic and were quite closer to the native culture. The study called for the key players, i.e., government officials involved in policymaking, the authors of the textbook, and the practitioners of ELT, to understand the politics of textbooks used for English language teaching, and, therefore, strive to institute an educational system which could be impartial and well-formed (Yaqoob, 2011; Wongsantativanich, 2019, Haberman et al., 2020).

Shah et al. (2013) argue that the knowledge provided in textbooks designed for the teaching of the English language at the secondary level is constructed socially, and the influential groups constructed the contents of these textbooks in agreement with their own ideological vision (Afzaal \& Xiangyi, 2020; Kanglong and Afzaal, 2020). Their case study conducted in Punjab highlighted that Islam is not only presented as a belief system in these textbooks but also a political ideology that must be accepted by each member of the society. The study noted that non-Muslim citizens received biased treatment in textbooks. In connection to that, vocabulary items in these textbooks were about Hajj, Zakat, and prayers, thus stressing the teachings of Islam. The researcher also noted that the textbooks did not promote critical thinking and civic participation among the students, and the topics on democratic values of freedom of speech, equality, and respect for cultural and religious diversity were not given due consideration in the contents of the textbooks (Shah et al., 2013).

Not only English language textbooks but also other academic subjects play their part in ideological constructs. The textbooks of social studies, history, and Pakistan studies contain several instances of ideological constructs (Zaidi, 2011; Afzal, 2015; Muhammad \& Brett, 2015; Pandhiani, 2016).

The official curriculum of Pakistan has been under great criticism for being subjective as it produced a one-sided narrative account of the historical events of the history and indoctrinated the negative views toward other religions and countries (Afzal, 2015). While comparing the Pakistan Studies textbooks taught at the secondary level in Pakistan, Afzal (2015) highlights that the attempts to bring reforms in the curriculum have failed. The researcher compared the issues including other religions, the United States, India, and terrorism dealt in the Cambridge board Pakistan Studies textbooks with the official (Matric) board books and noted that the substance and style of the books taught in 'O' level are superior to official (Matric) board books. The researcher noted that the different curricula construct different ideologies and highlighted that Cambridge textbooks being objective in nature depicted both sides of the story and engendered critical thinking. Moreover, the researcher also found that 'O' level students were more tolerant toward minorities by having better views on jihad. Therefore, the researcher suggested the government switch to Cambridge board Pakistan Studies textbooks as a viable means to warrant the curriculum reform (Afzal, 2015).

The review of the relevant literature highlights that the textbooks of English, Pakistan Studies, Social Studies, and History play their part in constructing desired ideologies. It is significant to point out that majority of the previous studies dealing with the analysis of textbooks taught either at the secondary level or at the intermediate level. However, no study has been published on the comparative analysis of embedded ideologies in textbooks of teaching English language (PTB and OUP) at the elementary level in government and private sectors in Punjab.

After gaining insights from the literature reviewed above, the researchers pursued their study on the analysis of ideological constructions embedded in textbooks (PTB and OUP) used for the teaching of the English language at the elementary level in Punjab. The current research aimed to analyze the English language textbooks being taught in the schools of Punjab from the CDA perspective. The study highlighted how textbooks of the English language taught at the elementary level construct certain ideologies.

The main objective of the current research is to bring out the construction of ideologies in English textbooks taught at the 
middle level in Punjab. It is delimited to English language textbooks prepared by Punjab Textbook Board for the teaching of English language at the middle level (class VII) in government sector schools and English language textbooks prepared by Oxford University Press, Oxford Progressive English implemented at the middle level (class VII) in private sector schools. It compares and contrasts both textbooks in terms of the construction of different ideologies.

The current study focuses on the following research questions:

1. What kinds of ideologies are being presented in English textbooks offered by the national curriculum followed at the middle level (class VII) in Punjab?

2. What kinds of ideologies are being presented in English textbooks offered by Oxford University Press followed at the middle level (class VII) in Punjab?

3. What are the similarities and differences in terms of construction of ideologies among the English textbooks offered by Oxford University Press and Punjab Textbook Board taught at the middle level (class VII)?

\section{METHODOLOGY}

The main focus of the current research was to investigate similarities and differences in terms of ideological constructs embedded in English (PTB and OUP) textbooks taught in the (private and government) schools of Punjab at the elementary level. Critical theory was adopted as a research paradigm for this qualitative method research. It was based on purposeful sampling, and the researchers ensured that the data selected should provide the text to analyze the ideological constructs and furnish the basis for comparative analysis.

The data for the current research has been taken from two series of English textbooks taught at the Elementary level. The age of the students at this level is usually between 11 to 13 years. Punjab Textbook Board (henceforth PTB) English textbooks class VII and Oxford University Press (henceforth OUP) Oxford Progressive English textbooks class VII particularly form the basis of data collection.

Lessons of both textbooks are sub-divided into essays, poems, narratives, autobiographies, articles, etc. All the lessons are directly or indirectly related to religion, patriotism, ideologies, gender, integrity, battle, prejudice, public, science, education, nature, vigour, and general knowledge. It is pertinent to mention that the term 'ideologies' has been used as an umbrella term further categorized into national, religious, political, and societal ideologies. The current research concentrates only on the content of those lessons which are associated with aforesaid ideologies. These lessons and contents are then critically analyzed using the selected framework.

The current research has employed Fairclough's (2003) analytical framework for critical discourse analysis to investigate ideological constructs embedded in the textbooks. In the current research, Fairclough's (2003) three-dimensional model was divided into sub-categories elaborated below, and the analysis of the selected text is based on these subcategories.

(a) Intertextuality

(b) Foregrounding and Backgrounding

(c) Presupposition

(d) Representation of Social Events

\section{DATA ANALYSIS}

The current study analyzed the ideological constructions embedded in English textbooks taught at the elementary level in Pakistan. The data were investigated to highlight the discourses embedded in the selected lessons and trace the ideologies employed in PTB and OUP textbooks. The comparative analysis of the data furnished the basis for judgment to highlight the differences in the subject textbooks in terms of their contribution to the construction of ideologies. The detailed analysis of the data is presented below:

\section{Intertextuality}

Intertextuality has a significant role in critical discourse studies, which solely aims at tracing features of other texts embedded within a particular text. The selected lessons from PTB and OUP textbooks are analyzed to highlight the intertextual references. (It has been noted that only one lesson from PTB offers instances of intertextuality, whereas no lesson from OUP contains intertextual instances.) In the lesson, Eid-ul-Azha' from PTB intertextual references have been incorporated through direct and indirect quotations in lesson Eid-ul-Azha.' An instance of indirect intertextuality can be witnessed when the writer mentions, "When the Rasool (PBUH) reached Madina Munawarah after leaving Makkah Mukkarramah, people told him that they used to celebrate two festivals every year." In these lines, the writer talks about the celebration of the religious festivals, referring back to the occasion of the first migration in Islam from Makkah to Madina when the Holy Prophet (PBUH) ordered to celebrate two festivals every year. In another instance, 'Should I give a better festival to celebrate every year'...He bade them to celebrate Eid-ul-Azha.' the writer has directly quoted the words of the Last Prophet (PBUH) to stress the desire for religious festivals and then indirectly quoted the text signifying the blessing of the festival of Eid-ul-Azha. In the same lesson, "Allah Almighty told Hazrat 
Ibrahim in a dream to sacrifice his son Hazrat Ismail". The writer is referring back to the dream of Hazrat Ibrahim, the rationale behind the celebration of Eid-ul-Azha. Intertextuality has successfully been employed to enhance the effect of the text. The instances of directly quoted and indirectly quoted references enhance the plausibility of the issue. In fact, the writer incorporated different references within the text to attach an element of credibility to the particular voices.

\section{Foregrounding and Backgrounding}

In the text, the authors give textual eminence to some impressions at the cost of the others and thus foreground certain concepts backgrounding the rest of the ideas. The instances of foregrounding and backgrounding were witnessed in one lesson of the PTB and two lessons of the OUP textbook.

The lesson 'The Quaid-i-Azam,' as the title suggests, describes notable glimpses of the entire life of the Quaid. However, the writer has foregrounded his political struggles in the making of Pakistan and backgrounded his personal life to create the desired impression on the minds of the readers. The writer's commitment to the topic and the text contained in the topic is significant as the lesson is confined to the title, and foregrounding is in complete synch with the title, Quaid-i-Azam, not Muhammad Ali Jinnah. Had it been about Muhammad Ali Jinnah, the writer would have given equal preference to all the aspects of his life. Most of the lesson is about his political struggles, and very little space has been specified for his personal life. At another point in the text, the role of Dr. Allama Muhammad Iqbal in the making of Pakistan is given due prominence; however, Iqbal's role in ensuring his commitment to the title of the lesson is somewhat backgrounded.

Pertinent instances of foregrounding and backgrounding may well be found in the selected lessons of the OUP textbook. In the lesson titled 'A Christmas Story,' the writer portrays the instances of Christmas festivals celebrated on the battlefield. However, it is, in fact, a letter by a British soldier, actually participating in World War-I, to his friend. The writer has foregrounded the Christmas Story and backgrounded the elements of the letter. In this way, the writer has substantiated his viewpoint.

Moreover, the story's setting is a war field, and the writer starts the narrative by depicting the warlike situation. The advent of the Christmas festival has brought cease-fire and thus backgrounded the situation of blood and horror. As the lesson proceeds, the soldiers from both armies celebrate the Christmas festival together and introduce each other. The narrator of the story introduces himself as a school teacher from Dorset. However, no instance can be traced highlighting his teaching practices. The writer has aptly foregrounded the current status of the narrator touching upon his involvement in the war. In the middle of the lesson, while celebrating the Christmas festival, the German soldier suggests a sports event of 'A football match.' "No one dies in a football match, no children orphaned. No wives become widows." Within the war situation, the writer has tactfully backgrounded the war and foregrounded the desire for peace. Apart from that, while demonstrating his point of view on a particular religious festival, the writer has deemphasized the war. He exclusively signified the title of the lesson and thus foregrounded the Christmas festival showing that religion can bring peace and unity among the nations who are at war against each other.

Furthermore, as the lesson was extracted from the Unit named 'War and Peace.' The writer has foregrounded 'peace' and backgrounded 'war,' indicating that peace is much needed. The writer tried to influence the mind of the reader with his desire for peace, earnestly desired by all.

The lesson 'Achievenemnt' of the OUP textbook also entails instances of foregrounding and backgrounding. Starting from the title, the writer has foregrounded the mountaineering expeditions of Nazir Sabir and specified a very little space to the other events of his life. Nazir Sabir has participated in politics, actively played his part as an advisor of a feature film. But one can notice that the writer has foregrounded only those events of his life that link with mountaineering in one way or the other; everything else has been backgrounded.

\section{Presupposition}

The presupposition is a kind of background assumption against which an action, theory, expression, or utterance makes sense or is rational. To illustrate how presupposition works in the text, the entire text of the selected lessons was scrutinized to find all the macrostructures. It was noted that one lesson of the PTB and two lessons of the OUP textbook contained the text carrying instances of presupposition.

From the title of the lesson 'Quaid-i-Azam,' the reader assumes that the text will exclusively mention the accomplishments of the founder of Pakistan, Muhammad Ali Jinnah. However, an in-depth investigation of the text suggests that some instances of the text carrying presupposition were also traced within the text. "The Congress and the British government ultimately agreed to the partition of India" presupposes that the Congress and the British government were in power at the time of the partition and greatly influenced the process of partition. In another instance, "Quaid-i-Azam took great interest in the formation of and progress of the Muslim Students Federation." presupposes that the Quaid had a great interest in the role of the young generation in politics. At the time of the making of Pakistan, he was passing from the last years of his life and wanted to transfer his political skills to the younger generation. 
In the lesson "A Christmas Story" the writer states 'First someone saw a white flag waving from the trenches opposite'”... "By this time, there were dozens of them walking towards us across no man's land and not a rifle between them." The white flag is considered an omen of peace worldwide, and the text presupposes that the soldiers are marching forward, not for bloodshed but for maintaining peace. In another instance, while introducing himself to fellow counterpart, the writer narrates "... I'm a school teacher from Dorest, in the west of England" presupposing that people from different professions participated in World War I. There is another instance of presupposition when the writer comments, "As I looked about me there were huddles of khaki and grey everywhere, all over no man's land, smoking, laughing, talking, drinking, eating." In this line, the word huddles presuppose that the soldiers from both armies were not professional soldiers; instead, they were forced to participate in the war. This is how a German soldier says, "A football match. No one dies in a football match, no children orphaned. No wives become widows." The response of both the armies towards war and their desire for peace is indicative of the fact that they have been forcefully put in the war.

Another lesson of the OUP textbook "Achievement," also comprises instances of the text carrying presupposition. " Nazir Sabir comes from Raminji village in the remote Chapurson Valley of Gojal in North Hunza," which presupposes that his passion for mountaineering is linked with his upbringing in the valley of Hunza. Again "Sabir and the expedition leader, Manzoor Hussain, survived a night spent huddled in a snow cave 150 meters from the summit of Mt Paiyu in China without sleeping bags" presupposes that Manzoor Hussein, the writer, was also a mountaineering conqueror. Spending the whole night in a snow cave presupposes that they were blessed with courage and stamina to bear the hard circumstances. In another instance, "Having pushed himself to the absolute limits of his strength and endurance during his moonlight climb, the next morning he achieved his life-long ambition" presupposes the passion and determination of Nazir Sabir that he climbed in not only the daylight but also the moonlight. The instances comprising the elements of presupposition indicate that Nazir Sabir was a passionate mountaineer and loved the expeditions.

\section{Social Representation of Events}

While investigating the representation of social events, it was noted that all the selected lessons (PTB and OUP) contained instances of embedded ideological constructs.

The title of the lesson, 'Eid-ul-Azha,' indicates that the students are going to learn about the religious festival of Islam. Pakistani community, being an Islamic republic, is a blend of religious and societal ideologies based on Islamic principles, and the lesson depicts these ideologies within the geographical bounds of the country, indicating that Pakistan and Islam are interrelated to each other in all aspects of identities.

The entire text of the lesson Eid-ul-Azha' depicts the religious festival of the Muslims disseminating a sense of brotherhood, selflessness, and sacrifice among the people. Therefore, the lesson presents a specific dimension of Muslim religious cum societal ideologies by depicting the universal significance of Islam covering all the aspects of human life.

In the lesson 'Eid-ul-Azha,' the writer borrowed the word 'Namaz' from the Urdu language instead of the word 'prayer' already available in the English language to exercise the power of indigenous language over a foreign language. The employment of such words indicates that the writer seems to consider Urdu as 'us' language having a closer affinity with Islam and Pakistan, and English as 'their' language having the least affinity with Islam.

The national identity of Pakistan as an Islamic republic is depicted in the lesson 'Eid-ul-Azha.' As Muslims of the entire world celebrate the religious festival of Eid-ul-Azha in a similar fashion, it creates Muslims as one ethnic group but divided on the basis of geographical boundaries. Therefore, the government supports Muslims of Pakistan to celebrate the festival with religious piety and thus translating its name as the Islamic Republic of Pakistan.

The title of the lesson "Quaid-i-Azam" is title employment used as an alternative for Muhammad Ali Jinnah, the founder of Pakistan. It is specific to the country's national ideology as Pakistan and Quaid-i-Azam are interrelated to each other in all aspects of national identity. The writer has depicted the events in the lesson that transformed him, i.e., Muhammad Ali Jinnah from a politician to the founder of Pakistan, i.e., the Quaid-i-Azam. The narrative of these events greatly impacts the learners' minds and thus significantly contributes to the construction of national ideologies. It is pertinent to mention that the contribution of Dr. Allama Muhammad Iqbal in the making of Pakistan is of historical significance. While learning about the life of the Quaid, the level of awareness of the students is further enhanced by referring back to the idea of a separate homeland for the Muslims as proposed by Dr. Allama Muhammad Iqbal, the idea that convinced the leader of great stature to lead the nation towards the making of Pakistan. The entire text of the lesson contributes significantly to construct the national ideology of Pakistan among the students.

While investigating the representation of social events in the selected lessons of the OUP textbook, it was noted that the lesson "A Christmas Story"' taken from the unit War and Peace' was constructed on the narrative of a soldier, in the form of a letter written to his friend, participating in the First World War. Certain instances of social representations in the lesson could not go unnoticed as they undoubtedly facilitated comprehension and investigation of diverse discursive constructions in the military, religious, and sports events. Various ideologies seem to have been ingrained by the publisher for the readers to read and interpret. Moreover, the writer has presented the celebration of the 
Christmas festival in the war field at no man's land and used the military discourse to start the story from the trenches. Then he gradually proceeds towards the religious discourse to present the celebration of the Christmas festival through voices of the soldiers greeting 'Christmas Morning,' another representation of a social event.

The interconnection of different scenes in the story is established through the title of the unit "War and Peace". The joint celebration of the Christmas festival by two hostile armies at the battlefield adds greater significance to the title of the unit, as the hostile forces which were once at war against each other are now at peace to celebrate the religious festival together. It also indicates the supremacy of the religion that has created the bond of friendship and generosity among the two armies.

The title of the lesson, 'A Christmas Story,' depicts the religious and societal ideology of the west (England and Germany). England and Christianity are interrelated to each other in all aspects of identities. An element of commitment on the part of the writer of the lesson can be witnessed that confines the story to the appropriately placed title of the unit, "War and Peace". The main event of the lesson is the Christmas festival, the setting of the event on the battlefield, and the peace prevails at the battlefield in the form of a sports event at the festival. All these events are closely interlinked with each other.

It is pertinent to mention that the book is prepared for the students of Pakistan. However, apparently, all these three events have nothing to do with the dominant social context of the country. Instead, it seems as if a deliberate effort has been made to infuse a ready-made narrative into the minds of the readers from an entirely different context presenting a story of 'their' (western) social context through the creation of a reasonable level of consent to accept diverse religious festivals gradually. Through the religious discourse, the writer seems to advocate peace through the teachings of a certain religion, convincing the readers that the geographical boundaries are the cause of hatred and horror. The way this very theme was constructed within the text is representative of the construction of certain ideologies through textbooks. These ideological perspectives are also significant within the construction of religious and societal ideology of western culture, leaving deep imprints on the students.

The entire text of the lesson 'A Christmas Story' creates the religious, political, military, and societal ideology of England. The readers are interconnected with Pakistan's national identity as an Islamic republic, and thus the lesson plays a significant role in creating specific religious, political, and military ideologies.

The lesson 'Achievement' entails details depicting the career of Pakistani mountaineer Nazir Sabir. The entire text of the lesson gives a specific direction to the representation of social events with a brief description of the multidimensional personality of Nazir Sabir and interprets the dangerous expeditions attracting ambitious mountaineers and promotes tourism in Pakistan. The writer has presented him as an ambitious adventurer, a patriotic mountaineer, a politician, and a film advisor and this portrayal seems to be positively affecting the minds of the young Pakistani learners of the English language. Nazir Sabir's success story promotes tourism and patriotism. He carried the national flag in all his expeditions and hoisted it at all the peaks he climbed, promoting the positive image of Pakistan. His treatment with his fellow mountaineers symbolizes the hospitality and comradeship of Pakistani mountaineers.

\section{DISCUSSION}

Critical Discourse Analysis of PTB English textbook taught at the elementary level provides a clear portrayal of the Pakistani society with diverse ideologies inculcating nationalistic, cultural, moral, and religious fervor among the readers. On the other hand, the OUP textbook offers the students ample opportunities to learn about the culture of other countries across the globe, especially the life depicted in the subject textbook sets up an idealistic impression in the minds of the Pakistani students, which is in complete contrast to the social life they are exposed to in Pakistan and thus takes them away from their national ideology.

The main purpose of these textbooks (PTB and OUP) is to provide an opportunity for the students to learn English language skills and enhance their vocabulary. The PTB has endeavored to achieve this aim while considering the sociolinguistic background of the students and foregrounded the political, societal, religious identities of the natives contributing significantly to the construction of national ideology. However, the content available for the students is confined to the national ideology, and students are bound to learning the English language within the confines of their own culture and religion, which is in the majority. On the other hand, the OUP textbook offered students entirely new dimensions taking them away from their culture and religion and getting them familiarized with the culture and religion of the country of the target language.

In both books, an exercise of power is apparent as the dominant imposes its thoughts and creates consent among the masses. However, this is in line with the students' national identity, whereas the OUP textbooks contribute to the creation of an amalgam of indigenous and alienated thought processes.

The depiction of the religious events in both textbooks significantly contributes to the construction of specific religious ideologies. The PTB textbook covers the Muslim religious festival Eid-ul-Azha enhancing the awareness of the students regarding the religion of the vast majority. However, the students studying in government schools are bound to learn about only one religion through the PTB, i.e., Islam. In the OUP textbook, the writer has presented a Christian religious festival in the background of World War. However, it has nothing to do with the construction of specific religious 
ideology as the depiction of the religious festival covered quite limited space. Thus students are rarely exposed to the religion of the people of the target language. The OUP textbook, specifically designed for the students of Pakistan, has nothing to do with the religious events of Pakistan.

The delineation of the specific personalities in the textbook is very important in the construction of ideologies. In the PTB textbook, the writer has given an outline of the life of the founder of Pakistan, the Quaid-i-Azam. The depiction of the life sketch of the personalities of such great stature contributes to the construction of national ideology. Whereas, in the OUP textbook, the writer has depicted the personality, Nazir Sabir, from the indigenous community, but its impact on the minds of the students, in terms of construction of ideologies, is not too significant. While comparing the lessons based on two personalities in two different textbooks taught at the same level, it was noted that the lesson in the PTB textbook based on the personality of a great stature has a remarkable impact on the minds of the students. On the other hand, there is no significant impact on the minds of the learners in terms of ideological construction in the lesson based on a personality in the OUP textbook.

The current study highlights that both textbooks focus on the culture of their own. PTB textbooks reflect Pakistani society, whereas the OUP textbook is replete with instances of Western culture and ideology. Wang (2016) has similar findings who noted the reflection of indigenous morals and national identity in the textbooks. Moreover, it also validates Dar \& Masroor (2019), who noted the cultural dissemination in the English language textbooks taught in Pakistan. These findings are in line with Yaqoob (2011), who indicated that PTB and OUP English textbooks taught at the secondary level were embedded with cultural ideologies representing different cultures influencing the worldviews of their readers. Taki (2008) also presented similar findings. These findings are further validated by Bakhtin (1981), who noted that the process of obtaining language proficiency leads to a process of ideological becoming.

It was noted in the current study that both textbooks were aiming to provide English language learning opportunities to the learners. However, the English language has been tactfully maneuvered by both of the textbooks as an ideologydriven tool employed in two different directions. Ideologies depicted in the PTB textbook were in line with the indigenous culture and identities, whereas ideologies presented by the OUP textbook were not compatible with the native culture. These findings validate Alimorad (2016), who noted the representation of incompatible ideologies and beliefs in textbooks implemented through the First Certificate Masterclass in Iran.

The current study noted that the authors of the PTB English textbook considered the sociolinguistic background of the students and foregrounded the political, societal, religious identities of the natives contributing significantly to the construction of national ideology. Therefore, it validates the findings of Hamidah (2017), who highlighted the author's mental awareness influencing the construction of specific ideologies. On the other hand, the content available in the OUP textbook significantly contributes to diverting students' attention from their very own culture and religion and makes them aware of the culture and religion of the country of the target language. These findings validate Liu (2020), who noted the implementation of dominant ideologies in the English language textbooks. Overall, it indicates that the authors of OUP and PTB textbooks were completely aware of the construction of desired ideologies, therefore validating Mirhosseini (2018), who noted the issues of ideology in English language education worldwide.

The results of the current study highlight that in both textbooks, an exercise of power is apparent, and the dominant seems to impose its thoughts to create consent among the masses. However, the hegemonic efforts of PTB are in line with the national identity of the students, whereas the OUP textbooks contribute to the creation of confused identities, an amalgam of indigenous and foreign thoughts. Wongsantativanich (2019) also noted that the dominant ideologies were presented in the English language textbooks. Furthermore, Abdollahzadeh and Banisad (2010) also noted similar findings and highlighted the exercise of hegemonic efforts in EFL textbooks.

The current study finds that both textbooks represent the religion of their country and thus construct their ideological vision. In a country of a Muslim majority, PTB textbooks represent the religion of the majority of the country, whereas OUP textbooks depict the events of the dominant religion of the target language country. Both struggles to impose their ideologies on the minds of the learners. These findings validate Ali et al. (2019), who noted the propagation of religious ideologies through textbooks taught at the intermediate level in Khyber Pakhtunkhwa, Pakistan. Shah et al. (2013) also noted a similar finding and highlighted that the contents of English language textbooks are manufactured by influential groups according to their ideological vision.

\section{CONCLUSION}

The present study highlights the ideological constructs embedded in PTB English textbooks taught at the middle level. This study demonstrates that the government officials (writers of the book) have put all their efforts into constructing/preserving the religious, societal, national, and political ideologies jointly contributing to Pakistan's national ideology. PTB English textbook taught at the middle level in Punjab specifically covers the sociolinguistic background of the students, foregrounds the dominant religious ideology. It reveals that while designing the English textbooks to teach at the middle level in Punjab, the government officials (the authors of the textbook) have particularly concentrated on the ideology of Pakistan, and Islam is presented as the dominant religion of the state. The author of the PTB English textbook has focused on the presentation of Muslim brotherhood and compassion. Moreover, the PTB English textbook contains content on national ideology, and the writer has carefully added the lesson on Quaid-i-Azam, primarily focusing 
on the national ideology. Thus, the stuff available in PTB English textbooks covers the indigenous setting and keeps the students within the country's national, religious, and geographical background and thus helps learners preserve their identity.

It has been noted that OUP textbooks taught at the elementary level in Punjab are embedded with certain ideologies. Through the depiction of different events, the writers of the OUP textbook have exercised power over the minds of the young learners and exposed them to other cultures. Besides, the OUP textbook is significantly contributing towards the creation of consent among the students to accept the alienated ideologies as their own. The presentation of religious festivals and social events entirely focuses on their domain. Moreover, the events of global significance are also presented with the contextual boundaries of 'their' domains. Thus, learning the English language through these textbooks is unconsciously creating consent among the students to accept foreign ideologies. Apart from that, the writers of the OUP textbook have considered English as a global language and structured the lesson with a global perspective. However, they could not break the chains of their religious and national identity and tried to express their religious and national identity as superior to others.

The current study highlights that both textbooks focus on the culture of their own. PTB textbooks clearly reflect Pakistani society, whereas the OUP textbook is replete with instances of Western culture and ideology. Both textbooks aimed to provide English language learning opportunities to the learners. However, the English language being ideologydriven has been maneuvered by both in their directions. The PTB English textbook has considered the sociolinguistic background of the students and foregrounded the political, societal, religious identities of the natives contributing significantly to the construction of national ideology. On the other hand, the content available in the OUP textbook puts all its efforts to divert the attention of the students away from their culture and religion and makes them aware of the culture and religion of the country of the target language. An exercise of power is apparent in both textbooks as the dominant seems to impose his thoughts to create consent among the masses. However, the hegemonic efforts of PTB are in line with the national identity of the students, whereas the OUP textbooks contribute to the creation of confused identities, an amalgam of indigenous and foreign thoughts. Besides, both the textbooks represent the religion of their country and thus construct their ideological vision. In a country of a Muslim majority, PTB textbooks represent the religion of the majority of the country, whereas OUP textbooks depict the events of the dominant religion of the target language country. Both struggles to impose their ideologies on the minds of the learners.

\section{RECOMMENDATIONS}

On the one hand, ideological constructs presented in PTB English textbooks highlight endeavours of the government preserving religious, national, political, and societal ideologies, and on the other hand, OUP English textbooks create consent among the students to accept their culture and ideologies. In light of the findings of the current study, the following suggestions will definitely be useful for future researchers:

(a) The current study suggests useful insights for a reformation of the current state of English language textbooks taught at the elementary level in Pakistan. It also raises awareness against the impact of stereotypical representations and misrepresentations on society's social and cultural beliefs in general and classroom settings in particular.

(b) The findings of the current research also propose valuable insights to textbook designers, authors, and syllabus designers in multiple dimensions. In this regard, syllabus designers are suggested to consider the ideological impacts of the textbooks.

(c)The current study calls for attention from both the government officials and the private sector school administration to focus on the quality content confined to their national ideology as well as provide useful insights to the learners to better live in global settings.

d) The entire study dealt with the comparative analysis of the PTB and OUP textbooks taught at the elementary level in Punjab. Therefore, longitudinal studies on the ideological constructions in PTB and OUP texts can be conducted based on the findings of the study.

\section{LIMITATION AND STUDY FORWARD}

It could only investigate selected texts from Punjab Textbook Board and Oxford University Press English textbooks used at the elementary level. However, much room for an extensive analysis is still left unaddressed, where the researchers may resort to exploring textbooks of other levels. The study employs a critical discourse dimension to unveil ideological constructions. However, various other educational parameters specific to the educational inquiries can be investigated through an entirely different educational approach.

\section{ACKNOWLEDGEMENT}

No specific financial or any other support was sought during the entire research process.

\section{AUTHORS CONTRIBUTION}

The main author facilitated the study by selecting the core texts and reviewed the entire study by transforming it into a 
researchable inquiry. He set the major objectives of the study and ensured conclusive findings conform to the major research inquiries.

The second author entirely focussed on unriddling the intricacies of micro and macro analysis of the textbooks through a critical discourse lens.

The third author facilitated in reviewing the entire research dynamics of the study, including the in-text and bibliographic referencing techniques of the article, and ensured employment of purposeful sampling.

The fourth author worked on reviewing the relevant literature the entire study hinges on.

\section{REFERENCES}

1. Abdollahzadeh, E., \& Baniasad, S. (2010). Ideologies in the imported English textbooks: EFL learners and teachers' awareness and attitude. Journal of English Language Teaching and Learning, 2(217), 1-17. Retrieved from https://elt.tabrizu.ac.ir/article_624.html

2. Afzal, M. (2015). History Textbooks, Ideology, and Attitudes in Government and Elite Pakistani Schools. Ideology, and Attitudes in Government and Elite Pakistani Schools (November 9, 2015). https://doi.org/10.21 $39 /$ ssrn. 2666720

3. Afzaal, M. (2020). Book review: Kennet Lynggaard, Discourse Analysis and European Union Politics (Palgrave Studies in European Union Politics), Discourse Studies, 22(5), 632-634. https://doi.org/10.117 7/1461445620921656

4. Afzaal, M., \& Xiangyi, J. (2020). Book review: Ken Hyland and Feng (Kevin) Jiang, Academic Discourse and Global Publishing: Disciplinary Persuasion in Changing Times. Discourse Studies, 22(3), 384386. https://doi.org/10.1177/1461445620905135

5. Alimorad, Z. (2016). Cultural values represented in First Certificate Masterclass taught in Iran: uncovering the hidden curriculum. SAGE Open, 6(1). https://doi.org/10.1177/2158244016636431

6. Ali, A., Hassan, S., \& Hanan, F. (2019). Propagation of Ideologies through Textbooks: A Study of Khyber Pakhtunkhwa English Textbooks. Global Regional Review, 4(1), 55-61. https://doi.org/10.31703/grr.2019(IVI).06

7. Apple, W. M. (2001). Ideology and curriculum. London: Routledge Education Books. https://doi.org/1 $0.2307 / 3339875$

8. Bakhtin, M. M. (1981). The dialogic imagination (C. Emerson \& M. Holquist, trans.) (Cambridge University Press). https://doi.org/10.2307/2497064

9. Dar, S., \& Masroor, F. (2019). Cultural Dissemination: A Case Study of English Text Books at Primary Level in Pakistan. International Journal of Innovation in Teaching and Learning (IJITL), 5(2), 33-48. Retrieved from http://irigs.iiu.edu.pk:64447/ojs/index.php/IJITL/article/view/699

10. Fairclough, N. (1989). Language and power. London: Longman. https://doi.org/10.1017/S0047404500016316

11. Fairclough, N. (1992). Discourse and social change. Cambridge: Polity Press. https://doi.org/10.1017/S 0047404500017309

12. Fairclough, N. (2001). Language and power (2nd ed.). Harlow: Pearson Education.

13. Fairclough, N. (2003). Analysing discourse: Textual analysis for social research. London New York: Routledge. https://doi.org/10.4324/9780203697078

14. Government of Pakistan (2006). National curriculum for English language. Grade I-XII Islamabad: Ministry of Education.

15. Haberman, P., Afzaal, M., Ghaffar, A., \& Alfadda, H. (2020). Various Roles in the Development of EFL Learners' English Skills. International Journal of Instruction, 13(4). https://doi.org/10.29333/iji.2020.13438a

16. Hamidah, S. C. (2017). The Representation of Gender Ideology in Indonesian Textbooks. ISLLAC: Journal of Intensive Studies on Language, Literature, Art, and Culture, 1(1), 201-223. https://doi.org/10.179 77/um006v1i12017p201

17. Jorgensen, M. \& Phillips, L. (2002). Discourse Analysis as Theory and Method. London: Sage Publication. https://doi.org/10.4135/9781849208871

18. Kanglong, L. and Afzaal, M. (2020). Lexical Bundles: A Corpus -driven investigation of Academic Writing Teaching to ESL Undergraduates. International Journal on Emerging Technologies, 11(5), 476- 482.

19. Liu, H. (2020). Ideologies in College EFL Textbooks-A Content Analysis Based on Critical Pedagogy. Journal of Language Teaching and Research, 11(6), 937-942. https://doi.org/10.17507/jltr.1106.09

20. McGrath, I. (2002). Materials evaluation and design for language teaching. Edinburgh: Edinburgh University Press.

21. Mirhosseini, S. A. (2018). Issues of ideology in English language education worldwide: An overview. Pedagogy, Culture \& Society, 26(1), 19-33. https://doi.org/10.1080/14681366.2017.1318415

22. Mohammed, M.A.S. (2015). The role of English language textbooks in the reproduction of racism. International Journal of English Language and Translation Studies, 3(1), 95-108.

23. Muhammad, Y., \&amp; Brett, P. (2015). Beyond binary discourses? Pakistan studies textbooks and representations of cultural, national, and global Identity. IARTEM e-Journal, 7(3), 74-101.

24. Pandhiani, S. (2016). Construction of cultural values and ideology in social studies textbooks: a critical discourse 
analytical perspective. The Women, Research Journal, 8, 27-39.

25. Rahman, T. (2002). Language, ideology and power. Karachi: Oxford University Press.

26. Sajid, J. M. (2015). Ideology in text books. Asian Journal of Humanities and Social Studies, 3(6), 575-581.

27. Saussure, F. D. (1960). Course in general linguistics. Bally, C. \& Sechehaye, A. (London: Peter Owen Ltd). https://doi.org/10.2307/538001

28. SDPI. (2002-03). The Subtle Subversion: The State of Curricula and Textbooks in Pakistan. Islamabad: Author.

29. Shah, S. K., Tariq, W., \& Bilal, M. (2013). Ideology in English textbooks: A case study of matric level books in Punjab. Research on Humanities and Social Sciences, 3(11), 113-120.

30. Shah, S. W. A., \& Pathan, H. (2016). Representation of western culture in 'O' level English language textbooks. In English Language Forum (ELF) (Vol. 18).

31. Simpson, J. A. (2009). The Oxford English Dictionary - CD-ROM Version 4.0: Windows/Mac Individual User Version. Oxford University Press, USA.

32. Taki, S. (2008). International and local curricula: the question of ideology. Language Teaching Research, 12, $127-$ 142. https://doi.org/10.1177/1362168807084503

33. Van Dijk, T. A. (1993). Principles of critical discourse analysis. Discourse \& society, 4(2), $249-283$. https://doi.org/10.1177/0957926593004002006

34. Van Dijk, T. A. (2001). Critical Discourse Analysis. In Schiffrin, D., Tannen, D. \& Hamilton, H. E., The Handbook of Discourse Analysis (pp. 352-371). Oxford: Blackwell.

35. Wang, D. (2016). Learning or becoming: Ideology and national identity in textbooks for international learners of Chinese. Cogent Education, 3(1), 1140361. https://doi.org/10.1080/2331186X.2016.1140361

36. Wongsantativanich, M. (2019). An Analysis of Ideologies in English Textbooks for Thai Students: A Case Study on Direct Method Reader for Thai Students. Journal of Kanchanaburi Rajbhat University, 8(1), 77-90. Retrieved from https://so03.tci-thaijo.org/index.php/KRUjournal/article/view/144915/143886

37. Westbury, I. (1990). Textbooks. Textbook publishers, and the quality of schooling. In D. Elliot and A. Woodward (eds), Textbooks and Schooling in the United States, 89th Yearbook, Part, 1, 1-22.

38. Wodak, R., \& Reisigl, M. (2001). The Semiotics of Racism. Approaches in Critical Discourse Analysis. Passagen Verlag. https://doi.org/10.4135/9780857028020

39. Yaqoob, M. T. (2011). Ideology and worldview in textbooks: A study of cultural aspects in ELT in Pakistan (Doctoral dissertation, Bahauddin Zakariya University, Multan.). Retrieved from http://prr.hec.gov.pk/jspui/bitst ream/123456789/1523/1/1233S.pdf

40. Yuen, K. M. (2011). The representation of foreign cultures in English textbooks. ELT Journal, 65, $458-466$. https://doi.org/10.1093/elt/ccq089

41. Zaidi, S. M. A. (2011). Polarisation of social studies textbooks in Pakistan. The Curriculum Journal, 22(1), $43-59$. https://doi.org/10.1080/09585176.2011.550770 